\title{
ENCODING AND DECODING IN THE TELEVISION DISCOURSE
}

Paper for the Council Of Europe Colloquy on "Training In The Critical "eading Of Televisual Language"。

Organized by the Council \& The Centre for Mass Communi-cation Research, University of teicester, September 1973

\section{Stuart $\mathrm{H}_{\mathrm{all}}$}

Centre for Cultural Studies University of Birmingham Edgbaston, Birmingham B15 2TT 
Two themes have been cited for this Colloguy: the highly focussed theme concerning the nature of the 'televisual language', and the very General and diffused concern with 'cultural policies and programmes'. At first sight, these concerns seem to lead in opposite directions: the first towards formal, the second towards societal and policy questions. Hy aim, however, is to try to hold both concerns within a single framework. My purpose is to suggest that, in the analysis of culture, the inter-connection between societal structures and processes and formal or symbolic structures is absolutely pivotal. I propose to organize my reflections around the question of the encoding/decoding moments in the communicative process: and, from this base, to argue that, in societies like ours, communication between the production elites in broadcasting and their audiences is necessarily a form of 'systematically distorted communication'. This argument then has a direct bearing on 'cultural policies', especially those policies of education, etc which might be directed to ards 'helping the audience to receive the television communication better, more effectively'. I therefore want, for the moment, to retain a base in the semiotic/Iinguistic approach to 'televisual language': to suggest, however, that this perspective properly intersects, on one side, with social and economic structures, on the other side with what Umberto Eco has recently called 'the logic of cultures' (1). This means that, though I shall adopt a semiotic perspective, I do not regard this as indexing a closed formal concern with the immanent organization of the television discourse alone. It must also include a concern with the 'social relations' of the communicative process, and especially with the various kinds of 'competences' (at the production and receiving end) in the use of that language (2).

In his paper (3) Frofessor Halloran has properly raised the question of studying "the whole mass comanication process", from the structure of the production of the message at one end to audience perception and 'use' at the other. This emphasis on "the whole commuicative process" is a comprehensive, proper and timely one. However, it is worth reminding ourselves that there is something distinctive about the product, and, the practices of production and circulation in communications which distinguishes this from other types of production. The 'object' of production practices and structures in television is the production of a message: that is, a sign-vehicle, or rather sign-vehicles of a specific kind organized, like any other form of communication or 
language, through the operation of coces, within the syntagmatic chains of a discourse. The apparatus and structures of production issue, at a certain moment, in the form of a symbolic vehicle constituted. vithin the rules of 'language'. It is in this 'phenomenal form' that the circulation of the 'product' takes place. Of course, even the transmission of this symbolic vehicle recuires its material substratum video-tape, film, the transmitting and receiving apparatus, etc. It is also in this symbolic form that the reception of the 'product', and its distribution between different segments of the audience, takes place. Once accomplished, the translation of that messaso into societal structures must be made again for the circuit to be completed. Thus, whilst in no way wantinf to limit research to folloring only those leads which emerge from content analysis" ( 4 ), we must recognize that the symbolic form of the message has a priveleged position in the commica-tive exchange: and that the moments of 'encoding' and 'decoding', though only 'relatively autonomous'in relation to the communicative pro-cess as a whole, are deterninate moments. $\mathrm{T}_{\mathrm{h}}$ e raw historical event cannot in that form be transmitted by, say, a television ne is-cast. It can only be signified within the aural-visual forms of the televisual language. In the moment when the historical event passes under the sign of language, it is subject to all the complex formal 'rules' by which language signifies. To put it paradoxically, the event must become a 'story' before it can become a communicative event. In that moment, the formal sub-rules of language are 'in cominance', without, of course, subordinating out of existence the historical event so signified, or the historical conseruences of the event having been signified in this way. The 'messace-form' is the necessary form of the appearance of the event in its passage from source to receiver. Thus the transposition into and out of the 'messace-form' or the meaning-dimension (or mode of exchange of the message) is not a randon 'moment', which we can talse up or ignore for the salse of convenience or simplicity. The 'message-form' is a cleterminate moment, though, at another level, it comprises the surface-movements of the communications system only, and revires, at another stage, to be integrated into the essential relations of communication of which it forms only a part.

From this general perspective, we may crudely characterise the communicative exchange as follows. The institutional structures of broadcasting, with their institutional structures and net:orlis of production, their organized routines and technical infrastructures, 
are recuired to produce the programe. Froduction, here, initiates the message: in one sense, then, tho circuit bogins here. Of course, the production process is franed throughout by meanings and ideas: lnowledgein-use concerning the routines of production, technical skills, pro- Fessional ideologies, institutional movledge, definitions and assumpti-ons, assumptions about the audience, etc fram the passage of the programe through this production structure. However, though the production structures of television originate the television message, they do not constitute a closed system. They arav topics, treatments, agendas, events, personnel, inages of the audience, 'definitions of the situation' from the wider socio-cultural and political system of which they are only a differentiated part. Fhilip Elliott has expressed this point succinctly in his discussion of the way in which the audience is both the source and the receiver of the television message. Thus circulation and reception are, indeed, 'moments' of the production pro-cess in television, and are incorporated, via a number of slieved and structured 'feed-backs', back into the production process itself. The consumption or reception of the television message is thus itself a 'monent' of the production process, though the latter is "preclominant" because it is the "point of departure for the realization" of the message. Production and reception of the television message are, not, therefore, identical, but they are related: they are differentiated moments within the totality formed by the commicative process as a whole.

t a certain point, however, the broadcasting structures must yield an encoded message in the form of a meaningful discourse. The institution-societal relations of production must pass into and through the modes of a language for its product to be 'realized'. This initiates a further differentiated moment, in which the formal rules of discourse and language operate. Before this message can have an 'effect' (however defined), or satisfy a 'need' or be put to a 'use', it must first be perceived as a meaningful discourse and meaningfully de-coded. It is this set of de-coded meanings which 'have an effect', influence, entertain, instruct or persuade, with very complex perceptual, cognitive, emotional, ideological or behavioural conseruences. In a determinate moment, the structure employs a code and yields a 'message': at another determinate moment, the 'message', via its decodings, issues into a structure. We are now fully aware that this re-entry into the structures of audience reception and 'use' cannot be understood in simple behavoural 
terms. Effects, uses, 'gratifications' are themselves framed by structures of understanding, as well as social and economic structures which shape its 'realization' at the reception end of the chain, and. which permit the meanings signified in language to be transposed into conduct or consciousness.

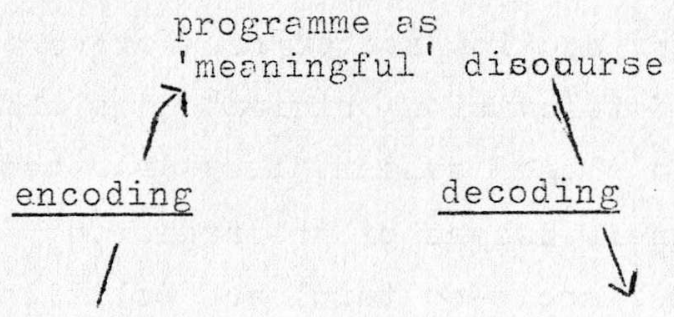

meaning

-structures 1 meaning: structures 11
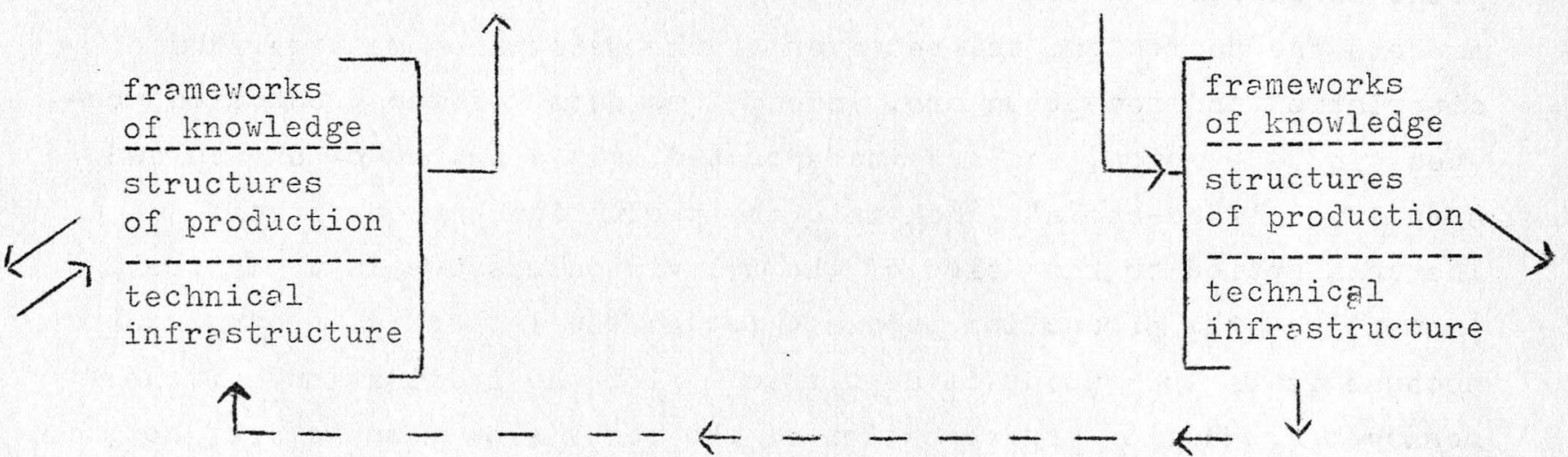

Clearly, hat we have called Mcanings I and Heanings II may not be the sane. They do not constitute en "immediate identity". The codes of encodins and decoding nay not be perfectly symetrical. The degrees of symmetry - that is, the degrees of 'understanding' and 'misuncerstanding' in the comunicative exchonge depend both on the degrees of symmetry/ a-symetry between the position of encoder-producer and that of the decoder-receiver: and also on the deprees of identity/non-identity between the codes which perfectly or imperfectly transmit, interrupt or systematically distort what has been transmitted. The lack of 'fit' between the codes has a great deal to do with the structural differences between broadcasters and audiences: but it also has something to do with the a-symetry bet een source and receiver at the monent of transformation into and out of the 'message-form'. That is called 'distortion' or 'misunderstandings' arise precisely from the lack of eruivalence between the two sides in the commuicative exchange. Once acain, this defines the 'relative autonomy' but 'determinateness' 
of the entry and exit of the message in its linguistic/meaning form.

The application of this rudimentary paradigm has already begun to transform our understanding of television 'content': and we are just beginning to see how it might also transform our understanding of audience reception and response as well. Beginnings and endings have been announced in communications research before, so we must be cautious. But there seems some ground for thinking that a new and exciting phase in audience research, of a uite new kind, may be opening up. it either end of the commicative chain, the use of the semiotic paradigm promises to dispel the lingering behaviourism which has dogged mass media research for so long. Though we know the television programe is not a behavioural input, lilse a tap on the lmee-cap, it seons to have been almost impossible for researchers to conceptualize the commicative procese without lapsing bacls into one or other variant of low-flying behaviourism. Ve know, as Cerbner has remarked, that representations of violence on the TV screen 'are not violence but messages about violence (5): but we have continued to research the cuestion of violence as if we were unable to comprehend the epistemological distinction.

Let us take an example from the drama-entertainnent area in television and try to show how the recognition that television is a discourse, a communicative not simply a behavioural event, has an effect on one traditional research area, the television/violence relation (6). Talie the simple-structur, early (and now children's) IV Vestern, modelled on the early Hollywood B-feature genre vestern: with its clear-cut, good/bad Nanichean moral universe, its clear social and moral designation of villain and hero, the clarity of its narrative line and development, its iconographical features, its clearly-registered climax in the violent shoot-out, chase, personal show-down, street or bar-roon duel, etc. For long, on both British and merican TV, this form constituted the predomi-nant drama-ontertainment genre. In uantitative terms, such films/pro- Grames contained a high ratio of violent incidents, deaths, woundings, etc. Thole cangs of men, whole troops of Indians, went down, nightly, to their deaths. Rescarchers - Himmelveit among others - have, hovever, suggested that the structure of the early IV/B-feature western was so clear-cut, its action so conventionalized, stylized, that most children (boys rather earlier than cirls, an interesting finding in itself) soon learned to recognize and 'read' it like a 'game': a 'cowboys-and-Injuns' game. It was therefore further hypothesized that Nesterns with this clarified a structure were less likely to trigger the 
aggressive initation of violent behaviour or other types of angressive 'acting-out' than other types of programmes with a high violence ratio which were not so stylized. But it is worth asling what this recomnition of the destern as a 'symbolic game' means or implies.

It means that a set of extrewely tightly-coded 'rules' exist whereby stories of a certain recognizable type, content and structure can be easily encoded within the vestern form. Whot is more, these rules of encoding' were so diffused, so symetrically shared as between producer and audience, that the 'message' was likely to be decoded in a monner highly symmetrical to that in which it had been encoded. This reciprocity of codes is, indeed, precisely what is entailed in the notion of stylization or 'conventionalization', and the presence of such rediprocal codes is, of course, what defines or malres possible the existence of a genre. Wuch an account, then, talses the encoding/decoding monents properly into account, and the case appears an unproblematic one.

But let us tale the argument a little further. Why and hov do areas of conventionalization arise (and disappear)? The lestern tale, of course, arose out of - though it quickly ceased to conform to - the real historical circunstances of the opening up of the kmerican lest. In part, what the production of the vestern fenre-codes achieved was the transfor.- mation of a real historical vest, selectively, into the symbolic or nythical 'West'. But why did this transformation of history into myth, by the intervention of a stylized set of codes, occur, for our societies and times, in relation to just this historical situation. This process, whereby the rules of language and discourse intervene, at a certain moment, to transform and 'naturelize" a specific set of histcrical circumstances, is one of the nost important test-cases for any semiology which seels to ground itself in historical realities. Ue know, and can begin to sketch, the elements which defined the operation of codes on history. This is the archetypal merican story, merica of the frontier, of the expanding and unsettled 'est, the 'virgin land' before law and society fully settle in, still closer to Wature than to Ia: and order. It is the land of men, of independent men, isolated in their confrontations with loture or Evil: and thus stories of masculine prowess, sill power and destiny: of men 'in the open air', driven to their destinies by inner compulsion and by external necessity - by Fate, or by 'the things a man just has to do': and thus a land where morality is inner-centered, and clarified - i.e. fully objectivated not in speech but in the facticities of gesture, gait, dress, 'cear', appeacance. I. Iand where women are either subordinate 
(whether as 'little homebodies' or ladies from 'back Last'): or, if somewhat more liberated - e.g. good/bad saloon girls - destined to be inadvertently and conveniently shot or otherwise disposed of in the penultimate reel: anc so on. If we wanted to make a strict semiological analysis, we could trace the specific codes which vere used to signify these elements within the surface-structures of particular films, plots, programes. What is clear is that, from this deep-structured set of codes, extrenely linited in its elenents, a sreat number of surface strings and transformations wero accomplished: for a time, in film and television, this deep-structure provided the talen-for-granted storyof-all-stories, the paradign action-narrative, the perfect nyth.

In the semiotic perspective, of course, it is just this surface variety on the basis of limited transformations which vould define the Western as an object of study. Nor would the transformations which we have ritnessed since the early days be at all surprising. We can see, and follow at least the basic nethods which would be recuired for us to account for the transformation of this simple-structure vestern into the psychological Western, the barocue lestern (Ieft llanded Gun?), the 'end-of-the-vest' Vestern, the comic lestern, the 'spaghetti' festern, even the Japenese and Hong-liong Nestern, the 'parody' Nestern (Butch Cossidy?), paradoxically, the return-of-violence vestern (The Nilc Bunch), or the domestic, soap-opera Vestern (the TV Virginian series) or the Latin-merican revolution vestern. The opening secuence of a film Iike Hud - one of the noment when the 'heroic' west begins to pass into the 'decline of the jest', in which the 'hero' appears criving through that familiar landscape in a Cadillac, or here the horse appears in the back of an Oldsmobile truck, far from indexing the break-up of the code, shows precisely how an opposite meaning can be achieved by the reversal of a limited number of. 'Iexical items' in the code, in order to achieve a transformation in the meaning.

From this perspective, the prolonged preoccupation of mass nedia researchors with the issue of violence in relation to the Vestern film appears more and more arbitrary, bizarro. If we refuse, for a moment, to bracket and isolate the issue of violence, or the violent episode from its matrix in the complex codes coverning the Eenre, ho many other, crucial kinds of meaning vere in fact transmitted whilst researchers were busy counting the bodies. This is not to say that violence was not an element in the IV vestern, nor to suggest that there were not cuite complex codes regulating the ways in which violence could be 
signified. It is to insist that what audiences wero receiving was not 'violence' but messages about violence. Once this intervening term has been applied, certain consequences for research and analysis follow: ones which irrevocably break up the smooth line of continuity offering itself as a sort of 'natural logic', hereby connections could be traced bet:een shoot-outs at the of Corral, and celinguents lnocking over old lacies in tho street in Jcunthorpe.

The violent element on string in the nerrative structure of the simple-structure .estern - shoot-out, bral, abush, banl-raid, fisifight, woundins, duel or wassacre, like any other semantic unit in a structured discourse cannot signify anything on its own. It can only signify in terms of the structured meanings of the messoce as a whole. Further, its signification depends on its relation - or the sum of the relations of stmilarity and difference - with other elements or units. Burgelin (7) has long ago, and definitively, reminded us that the violent or jcled acts of a villain only mean sonething in relation to the prescnce/absence of rood acts.
we clcarly cannot craw any valid inferences from a simple enumeration of his vicious acts (it makes no difference whether there are ten or tenty of them) for the crux of the natter obviously is: what meaning is conferred on the vicious acts by the fact of their juxtaposition with the single good action...one could say thot the neaning of what is frequent is only revealed by opposition to what is rare ...The whole problem is therefore to identify this rare or missing item. Structural onalysis provides a way of approaching this problem which traditional content analysis does not.

Indeed, so tightly constructed was the rule-govorned moral economy of the simple-structure destern, that one good act by a 'villain' not only could, but apparently had to lead to some modification or transformation of his end. Thus, presence of numorous bad-violent acts (marlied) / absence of any good-redeeming act (unmerked) = unrepentant villain: can be shot dom, without oxcuse, in finaz episode and mates a brief and 'bad' or undistinguished death (provided the hero does not shoot the villain in the back, or unawares, and does not draw first). But, presence of baci-violent acts (marled) f presence of single goodredeoming act $($ marled $)=$ possible salvation or regeneration of the villain, death-bed reconciliation with hero or former cronies, restitution to wronged comunity, at the very least, lingering and 'good' cleath. That, we may now ask, is the meaning of 'violence' when it only appears and signifies anything within the tightly-organized 
moral economy of the vestern?

Te have been arguing (a) the violent act or episode in a vestern cannot signify in isolation, outside the structured field of meanings which is the film or programme; (b) it signifies only in relation to the other elements, and in terms of the rules and conventions which govern their combination. We must now add (c) thatthe meaning of such a violent act or episode cannot be fixed, single and unalterable, but must be capable of signifying different values depending on how and with what it is articulated. As the signifying element, among other elements, in a discourse, it remains polysemic. Indeed, the vay it is structured in its combination with other elenents serves to delimit its meanings within that specified field, and effects a 'closure', so that a preferred meaning is suggested. There can never be only one, single, univocal and determined meaning for such a lexical item, but, dependine on how its interration within the code has been accomlished, its possible meanings will be organized within a scale which runs from doninant to subordinate. ind this of course has consequences for the other - the reception - end of the communicative chain: there can be no law to ensure that the receiver will take the preferred or dominant meaning of an episode of violence in precisely the way in which it has boen encoded by the producer.

Typically, the isolation of the 'violent' elenents from the restern by researchers was made on the presumption that all the other elements setting, action, characters, iconography, movement, codduct and appearance, moral structure, etc - vere present as so many inert supports for the violence: in order to varrant or endorse the violent act. It is now perfectly clear that the violence might be present only in orcer to warrant or endorse the character. We can thus sketch out more than one possible path of meaning through the way in which the so-called 'content' is organized by the codes. Tale that ubiquitous semantic item of the simple vestern: hero draws his cun, faster than anyone else (ho seems alvays to have known how), and shoots the villain with bull's-eye aim. To use Gerbner's term (8), what norm, proposition or cultural signi-fication is here signified? It is possible to decode this item thus: "The hero figure knows how to draw his gun faster, and shoot better than his eneny: when confronted by the villain, he shoots him dead with a single shoti". This might be called a 'behavioural' or 'instrumental' interpretation. But - research suggests - this directly behavioural 'messace' has been stylized and conventionalized by the intervention of a highly organized set of codes and genre-conventions (a code-of-codes, 
or meta-code). The intervention of the cocies appear to have the effect of neutralizing one set of meanings, while setting another in motion. Or, to put it better, the codes effect a transformation and dis lacement of the same denotative content-unit from one reference-code to another, thereby effecting a transformation in the signification. Berger and Iuclmann (9) have argued that 'hsbitualization' or 'sedimentation' serves to routinize certain actions oi meanings, so as to free the foreGround for new, innovative meanings. Turner (10) and others have shown how ritual conventions redistribute the focus of ritual porfornances fron one domain (e.g. the enotional or personal) to another (e.g. the cognitive, cosmological or social) domain. Freud (11), both in his analysis of ritualization in symptom-formation and in the drean-work, has shown the pivotal position of condensation and displacenent in the encoding of latent materials and meanings through manifest symbolizations. Bearing this in mind, we may speculativelt formulate an alternative connotative 'reading' for tho item. "To be a certoin kind of nan (hero) means the ability to master all contingencies by the demonstration of a practised and professional 'cool'" This reading transposes the sane (denotative) content from its instrumental-behavioural connotative reference to that of decorum, conduct, the idiom and style of (masculine) action. The 'message' or the 'proposition', now, woulc be understood, not as a message about 'violence' but as a message about conduct, or even about professionalism, or perhaps even about tho relation of professionalism to character. And hero we recall Robert warshow's intuitive observation that, fundanentally, the vestern is not 'about' violence but about codes of concuct.

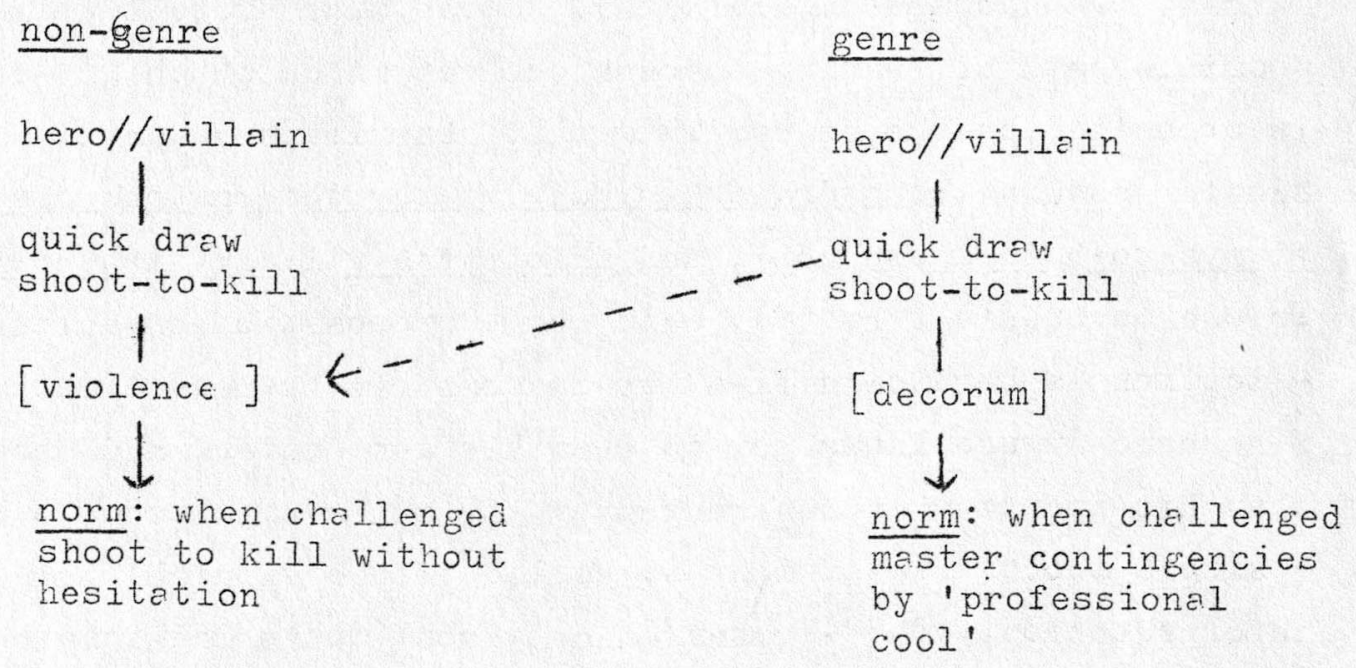


I have been trying to suggest - without being able to take the example very far - how an attention to the symbolic/linguistic/coded nature of commications, far from boxing us into the closed and formal universe of signs, precisely opens out into the area where cultural content, of the most resonant but 'latent' kind, is transmitted: and especially the manner in which the interplay of codes and content serve to displace meanings from one frame to another, and thus to bring to the surface in 'disguised' forns the repressed content of a culture. It is vorth, in this connection, bearing in minc Lco's observation that (12) "Semiology shows us the universe of ideologies arranged in codes and sub-codes within the universe of signsi: Hiy own view is that, if the insights won by the advances in a semiotic perspective are not to be lost within a new lind of formalism, it is increasingly in this direction that it must be pushed. ( 13 )

Let us turn, now, to a different area of programing, and a different aspect of the operation of codes. The televisual sign is a peculiarly complex one, as ve innow. It is a visual sign with strong, supplementary aural-verbal support. It is one of the icoric signs, in Feirce's sense, in that, thereas the forn of the written sign is arbitrary in relation to its signified, the iconic sign reproduces certain elenents of the sicnified in the form of the signifier. As Feirce says, it "possesses some of the properties of the thing or object represented" (14). letually, since the iconic sign translates a three dimensional world into two representational planes, its 'naturalism' with respect to the referent lies not so much at the encoding side of the chain, but rather in terns of the learned perceptions with which the viever decodes the sign. Thus, as Eco has convincingly argued, iconic signs 'look like objects in the real world', to put it crudely (e.g. the photograph or draing of a /cow/, and the animal /cow/), because they "reproduce the conditions of perception in the receiveri". (15). Ihese conditions of 'recognition' in the viewer constitute some of the most fundanental perceptual codes which all culture-inembers share. How, because these perceptual codes are so widely shared, denotative visual signs probably give rise to less 'misunderstandings' than linguistic ones. A lexical inventory of the Lnglish language vould throw up thousands of words which the ordinary spealer could not denotatively comprehend: but provided enough 'infor-mation' is given, culture-nembers would be able or competent to decode, denotatively, a much vider range of visual signifiers. In this sense, and at the denotative level, the visual sign is probably a more 
universal one than the Iinguistic stgn. Whereas, in societies like ours, Iinguistic competence is very unecually distributed as between difforent classes and serments of the population (predominantly, by the family and the education system), what we might call 'visual competence', atthe denotative level, is more universally diffused. (It is worth reminding ourselves, of course, that it is not, in fact, 'universal', and that ve are dealing with a spectrum: there are lsinds of visual representation, short of the 'purely abstract', which create all kinds of visual puzzles for ordinary viewers: e.g. cartoons, certain rinds of diagramatic representation, representations which employ unfamiliar conventions, types of hotcgraphic or cinematic cutting and editing, etc). It is also true that the iconic sign may support 'mis-readings' simply because it is so 'natural', so 'transparent: ilistakes may arise here, not because we as vievers cannot literally decode tho sign (it is perfectly obvious what it is a picture of), but because we are tempted, by its very 'naturalisation' to 'misread' the image for the thing it signifies (16). Iith this important proviso, however, we would bo surprised to find that the majority of the television audience had much difficulty in literally or cienotatively identifying what the visual signs they see on the screen refer to or signify. Whercas most peole recuire a lengthy process of education in order to become relatively competent users of the language of their specch comunity, they seem to pick up its visual-perceptual codes at a very early age, without formel training, and are quiclily competent in its use.

Tho visual sign is, however, also a connotative sign. nd it is so pre-eminently within tho discourses of modern mass commication. The level of connotation of the visual sign, of its contextual reference, of its position in the various associative fields of meanings, is precisely the point where the clenoted sign intersects with the doep semantic structures of a culture, and takes on an ideological dimension. In the advertising discourse, for examle, we might say that there is almost no 'purely denotative' communication. Every visual sign in advertising 'connotes' a qualjty, situation, value or inference Jhich is present as an implication or implied neaning, depending on the connotational reference. $\therefore e$ are all probably familiar with Barthes' example of the /sweater/, which, in the rhetoric of advertising and fashion, alvays connotes, at least, 'a warm carment' or 'leepine warm', and thus by further elaboration, 'the coming of vinter' or 'a cold day'. In the specialized sub-codes of fashion, /sweater/ may connote 'a 
fashionable style of haute couture', or, alternatively, 'an informal style of dress'. But, set a ainst the right backeround, and positioned in the romantic sub-code, it may connote 'Ions autum ralk in the woods' (17). Connotational codes of this order are, clearly, structured enough to signify, but thoy are more 'open' or 'openwonded' than denotative codes. What is more, they clearly contract relations with the universe of ideolo- Gies in a culture, anc with history and ethnography. These connotative codes are the 'Iinguistic' moans by which the domains of social Iife, the sementations of culture, poier and ideology a.e mado to signify. They refer to the 'maps of moaning' into which any culture is organized, and those 'maps of social reality' have the whole range of social meanings, practices and usages, power and interest 'writton in' to them. Connoted signifiers, Barthes has reminded us, "have a close commication with culture, Inowledge, history, and it is through them, so to spoak, that the environmental world invades the linguistic and semantic system. They are, if you like, the framents of ideologyil. (18)

The donotative level of the televisual sign may be bounded within certain, very complex but limited or 'closed' codes. But its donnotative Ievel, though bouncled, remains open, subject to the formation, transformation and docay of history, and fundamentally polysemic: any such sign is potentially mappoble into nore then one connotative configuration. 'Iolysemy' must not, hovever, be confused with pluralism. connotative codes are not equal amons themselves. iny society/culture tends, with varying degrees of closure, to impose its segmentations, its classifications of tho social and cultural and political world, upon its membors. There remains a dominant cultural order, though it is neither univocal nor uncontested. This uestion of tho 'structure of dominance' in a culture is an absolutely crucial point. le may say, then, that the different areas of social Iife appear to be mapped out into connotative domains of dominant or proferred meaninss. Hew, problenstic or troubling things and events, which breach our expectancies and run counter to our 'common-sense constructa', to our 'taken-for-granted' Inowledme of social structures, must be assigned to their connotational domains before they can be said to 'make sense': and the most comon vay of 'mappins them' is to assign the new within some donain or other of the existing 'maps of problomatic social reality'. Je say dominant, not 'determinod', bocause it is always possible to order, classify, assign and decode an event within more than one 'mappings'. But we say 'doninant' because there exist a pattern of 'preferred readings', and these nappings both have the institutional/political/ideological. ordor imprinted in thein, and have 
themselees becone institutionalized (19). The domains of 'preferred map-pings' have tho wholo social order embedded in them as a set of meanings: practices and belicfs, the cveryday knowlecige of social structures, of how things work for all practical purposes in this culture;, the rank order of power and interost, and a structure of legitinations and sanctions. Thus, to clarify a 'misunderstanding' at the denotative level, we noed primarily to refer to the immanent world of the sign and its codes. But to clarify and resolve 'misunderstandings' at the level of connotation, we must refer, through the codes, to the rules of social life, of history and life-situation, of econonic and political porer, and, ultimatoly, of iccology. Turther, since these connotational mappings are 'structured in dominancer but not closed, the communicative process consists, not in the unproblematic assignnent of evory visual iten to its position within a set of prearranged codes, but of performative rules - rules of competencer anc use, of logics-in-use - which seck to enforce or pre-fer one sementic donain over another, and rule items into and out of their apropriate noaning-scts. Formal somiology has too often noglected this lovel of interpretive work, though this forms in fact the ceep-structuro of a root deal of broadcast time in television, especialjy in the political and other 'sensitive areasi of progroming. In spearing of dominant meanings, thon, we are not simply talline about a one-sided process, which coverns how any event vill be sicnified (wo might thinl, for oramole, of the recent coup in Chile): it also consists of the 'work' rojuired to enforce, win plausibi-lity for and comond as iegitimate a ce-coding of the event within the dominant definition in which jt has been connotatively simnified. Dr Terni remarked, in his paper (20) that, By tho vord reading we noan not only the capecity to identify and decode a certain number of signs, but also the subjective capacity to put them into a creative rolation between themsclves and with other signs: a capacity hich is, by itsolf, the condition for a complete awarenoss of one's totol enviroment". Our only uarrel here is with the notion of "subjective capacity", as if the denotative reforence of the televisual. sign is an objoctive process, but the connotational and connective level is an inclividualized and private matter. Gute the opposite secms to us to be the case. The televisual process takes 'objective' (i.e. systemic) responsibility precisely for the relations which disparate signs contract uith one another, and thus continually delimits and prescribes into whot "awareness of ones total environment" these items are arranged. 
This brings us, then, to the key uestion of 'misunderstandings' between the oncoders and decoders of the television message: and thus, by a long but necessary detour, to the matter of 'cultural policies' designed to 'facilitate better communication', to 'make commication more effective'. Television producers or 'encoders', who find their message failing to 'get across' are frequently concerned to straighten out the kinlss in the comunicativo chain, and thus to facilitate the 'effectiveness' of their mossages. areat deal of research has been devoted to trying to discover how much of the messafe the audience retains or recalls. At the denotative level (if we can moke the anolytic distinction for the moment), there is no doubt that some 'misunderstandings' oxist, though we have no real idea how widespread this is. And we can see possible explanations for it. The viener does not 'speals the language', figuratively if not literally: he or she cannot follow the complex logic of argument or exposition: or the concepts are too alien: or the editing (which arranges items within an expository logic or 'narrative', and thus in itself proposes connections between discrete things) is too swift, truncated, sophisticeted; ctc. At onother level, encoders also mean that their audience has 'mode sense' of the message in a vay different from that intendod. What /really means is that vievers aro not operating within the dominant or preferred code. The icleal is the per- fectly transparent communication. Instead, what they have to confront is the fact of 'systematically distortod communication'.

In recont years, discropancies of this kind are usually accounted for in terms of individually 'aberrant' readings, attributed to 'selec-tivo perception'. 'Selcotivo perception' is the door via wich, in recent research, a residual pluralism is reserved within the sphere of a highly structured, a-symetrical cultural operation. Of course, there will always be individual, private, vartant readings. Lut my om tontative view is that 'selective perception' is almost never as seloctive, random, or privatized, as the concept sugfests. The patterns oxhibit more structuring and clustering than is normally assumed. ny not aproach to audionce studies, via the concopt of 'de-coding' would have to begin with a criticue of 'selective perception' theory.

Eco has recently pointed to another, intermediary, levol of structuration, between competence in the dominant code, and 'aberrant' individual readings: that level provided by sub-cultural formations. But, since sub-cultures aro, by definition, differenticted articulations within a culture, it it more useful/this nediation within a sonewhat different framoworls. (2I) 
The very general typology stetched below is an attempt to reinterpret the notion of 'misunderstandings" (which we fincl inadequate) in terms of certain broadly-defined socictal perspectives which audiences might adopt tovards the televisual message. It attempts to apply Gramsci's work on 'hegemonic' and 'corporate' ideological formations (22) and Farlin's rocent work on types of meaning systems. I should like now (adapting Faricin's schoma) to put into discussion four 'ideal-type' positions from which decodings of mass commuications by the audience can be mado: and thus to re-present the common-sense notion of 'nisunder-standings' in terms of a theory of 'systematically cistorted communica-tionsi (23).

Iiteral or denotative 'errors' are relatively unproblematic. They represent a find of noise in the chonnel. But 'misreadings' of a message at the connotative or contextual level are a different matter. They have, fundamentally, a societal, not a commicative, basis. They signify, at the 'message' level the structural conflicts, contradictions and negotiations of economic, political and cultural life. Tho first position we want to identify is that of the dominant or hecenonic code. (There are, of course, many different codes and sub-codes recuired to produce an event vithin the dominant cole). When the viewer takes the comoted neaning from, say, a telcvision newscast or current affairs programe, full and straight, and decodes the message in tems of the refercnco-code in which it has been coded, we ight say that the viever is operating inside tho dominant code. This is the ideal-typical case of 'perfectly transperent commication', or as close as we are likely to come to it 'for all practical purposes'. liext (here we are amplifyine Farkin's model), we would want to icentify the professional code. This is the code (or set of codes, for we are here deoling with what might be bettor called neta-codes) which the professional. broadcasters employ whon transmittine a message which has olready been signified in a hegenonic nanner. The professional code is 'relatively independent' of the dominant code, in that it applics criterio and opere-tions of its ovn, es ccially those of a technico-practical nature. The professional code, howevor, operatos rithin the 'hegemony' of the cominent code. Indeed, it serves to roproduce the dominant cofinitions precisely by bracleteing the hegenonic quality, anc operating with professional. codings which relate to such questions as visual vality, news and presentational values, televisual quality, 'professionalism', etc. The hegemonic interpretation of the politics of horthern Ireland, or the Uhilcan coup or the Industrial Relations Bill are given by political elites: the perticular choice of presentational occasions and formats, the selection of personnel, tho choice of images, the 'staging' of 
debates, etc are selected by the operation of the professicnal code. (24) How the broadcasting professionals are able both to operate with 'relatively autonomous' codes of thoir own, while acting in such a way as to reproduce (not without contradiction) the hegemonic signification of events is a complox mattor mich cannot be furthor spolled out here. It must suffice to say that tho professionals are linked with the defining clites not only by the institutional position of brcadoasting itsolf as an 'ideological apparatus' (25), but moro intinately by the structure of access (i.e. the systematic 'over-accessing' of olite personnel. and 'clefinitions of the situation' in television). It may even be said that tho profosstonal codes sorve to reproduce hemomonic defini-tions specifically by not overtly biassing their operations in their direction: idcological reproduction therefore talses place here inadvertent-Iy, moonsciously, 'behind non's backs'. Of course, conficts, contradic-tions and even 'misunderstancings' regularly tako placo bet een the cominant and the professioncl significations and their signifying agencies. The third position we would identify is that of the negotiated code or position. lajority audiences probably understand quite ade uately what has been dominently defined and profossionally signjified. Tho dominent definjtions, however, are hegenonic precisely because they represent definitions of situations and events which are 'in dominance', and which are blobal. Woninant definitions connect ovents, implicitly or explicitly, to erand totalizations, to the groet syntagnetic views-of-the-vorld? they talce 'Iargo viovs' of issucs: they relato ovents to 'the national interest" or to the level of geo-politics, even if they mole these connections in truncated, inverted or nystified vays. The definition of a "hogunonic' vicupoint is (a) that it defines within its tems the wontal horizon, the univorse of possible neenings of a whole sacicty or culture; and (b) that it carries with it the stany of logitimacy - it appoars coterminous with what is 'natural', 'inovitalle', 'to'en for crantedi about the social order. Docodins within tho nesotiated version contains a mixture of adaptive and opositional olemonts: it aclno led- ges the legitimocy of the hegemonic dofinitions to malo tho crond signifi-cations, while, at a nore restricted, situational lovel, it males its own cround-rules, it operates with 'cxcertions' to tho rule. It accords the priveleged position to the dominant definition of events, whilst reserving the right to make a more nerotiated opplication to 'Iocal conditions', to its own more corporate positions. This negotiated version of the dominont ideology is thus shot through with contradic-tions, though these are only on certain occasions brought to full 
visibility. Negotiated codes operate through that we might call particular or situated logics: and these logics arise from the differential position of those who occupy this position in the spectrum, and from their differential and unecual relation to power. The simplest example of a negotiated code is that which governs the response of a worler to the notion of an Incustrial helations Bill limitine the right to strike, or to arguments for a wagcs-freeze. ..t the lovel of the national-interest economic debate, he may adopt the hogenonic definition, acreoing that 'we must all pay ourselves less in order to corbat inflation', etc. This, however, may have littlo or no relation to his wilingness to go on strike for better pay and conditions, or to oppose the Incustrial Relations Bill at the level of his shop-floor or union orsanization. Ne suspect that tho ercat nejority of so-celled 'misunderstandings' arise from the disjunctures between hegemonic-dominant encodings and negotiated-corporate decodings. It is just these mis-matches in tho levels which most provole defining elites and professionals to identify a 'failure in communications'. Finally, it is possible for a viever perfectly to unclerstand both the Iiteral and connotative inflection eiven to an event, but to determine to decode the message in a globally contrary vay. He cietotalizes the message in the preferred code in order to retotalize the message within some altemative frame orl of referonce. This is the case of the viewer who listens to a debate on the need to limit vages, but who 'reads' every mention of 'the national interest' as 'class interest'. He is operating with what we must call an oppositional code. One of tho most sienificant political moments (thoy also coincide with crisis-points within the broadcasting organizations themselves for obvious reasons) is the point when events wich are normally signified and docoded in a nogotiated way begin to be given an ompositiohal reading.

The question of cultural policies now falls, awlwardiy, into placo. Then dealing with social commications, it is extrencly difficult to identify as a neutrai, educational goal, tho task of 'improving comu-nications' or of 'naling comunications more effective', at any rate once one has passed beyond the strictly donotative lovel of the message. The oducator or cultural policy-moker is porfoming one of his most partisan acts whon he colludes with the re-signification of real conflicts and contradictions as if they were simply linis in the commicative chain. Lenotative nistakes aro not structurally significant. But connotative and contextual 'misunderstandings' are, or can be, of the highest significance. To interpret what are in fact cssential 
elements in tho systematic distortions of a socio-comnunications system as if they tochical favits in transmission is to misrcad a decp-structure process for a surface phonomenon. The decision to intorvene in order to malse tho hegenonic codes of dominant clites more effoctive and transparent for tho majority audionce is not a tochnically neutral, but a political one. To 'missead' a political choice as a technical one represents a type of unconscious collusion with the doninant intorests, a form of collusion to which social science researchors are all too prone. Thouen the sourcos of such mystification are both social and stmctural, the actual process is greatly facilitated by the oporation of discrepant codes. It would not be the first time thet scientific researchors had 'unconscious-Iy' played a part in the reproduction of hosemony, not by ononly submitting to it, but simply by operating the 'professional braclet'.

\author{
Stuart Holl \\ Centre For Cultural \\ Studies \\ University of -hanming- \\ dgbaston, Dimingham \\ B15 2115
}

Soptember 1973 
1. Umberto Eco, "Does The Public Harm Television?" Cyclostyled paper for Italia Prize Seminar, Venice (1973).

2. Cf: Dell Hymes' critique of transformational approaches to lan-guage, via concepts of 'performance' and 'competence'in "On Communicative Competence", in Sociolinguistics, ed. Pride \& Holmes, Penguin Education (1972)

3. J.D.Halloran, "Understanding "elevision". Paper for Council of Europe Lolloquy. Leicester (1973)

4. Halloran, ibid.

5. Gerbner, et al , Violence In TV Drama: A Study Of Trends \& Symbolic Functions. Annenberg ichool, Univ。 of Pennsylvania. (1970)

6. This example is more fully discussed in Part II, "New Approaches To Content", Violence In The TV Drama-ieries. CCS Report to Home Office Inquiry Into TV/Violence, Centre for Mass Comm. hesear-ch. Shuttleworth, Camargo, Lloyd and Hall。 Birmingham U。 (Forth-coming).

7. O.Burgelin, "Structural "nalysis \& Mass Communications". Studies In Broadcasting, No.6. Nippor Hoso Kyokei. (1968)

8. For 'proposition-analysis', see Gerbner, "Ideological Ferspectives \& Political "'endencies in News Reporting", Journalism Quarterly 41 (1964) and E.Sullerot, "Use tutude $\mathrm{\nu}_{e}$ Presse..", Iemps Modernes vol.XX, No 226 (1965). For 'norm-analysis', Cf: "uerbner, in Violence \& The Mass Media, Task Horce Report to Hisenhower Comm-ission on Causes \& Frevention of Violence, US Printing Office (1969)

9. Berger \& Luckmann, Social Construction Of teality. Penguin (1971)

10. V.W.Turber, The Ritual Process. Houtledge \& Kegan Paul. (1969)

11. Especially in Interpretation Uf reams.

12. U.Eco, "Articulations of Cinematic Code", Uinemantics $I$.

13. Cf: developments of this argument in S.Hali, "Determinations of 'the News Photograph", WPCS 3 (CCS, 1972), and "Open \& Closed Uses of Structuralism" (stencilled: CCS 1973).

14. C.S.Peirce, Speculative Grammar

15.

16.

17.

$18 \frac{1}{2}$ Eco, op.cit.

Cf: S.HaII, "Deperminations..", op.cit.

R.Barthes, "Rhetoric of The Image". In WPCS I. CCS, B'ham (1971)

R.Barthes, Elements of ímiology. Cape (1967)

19. Cf: the section on "Codes of Connotation", in S.Hall, op.cit., and more generally, in "Deviancy, Politics \& The "edia"in Social Control Deviance \& Dissent, ed. Vic Intosh \& Rock. Tavistock (Forthcoming).

20. P.Terni. ${ }^{1.1}$ emorandum. Council of Hurope Colloquy, Leciester. (1973)
22. Antonio Gramsci, Selections From Prison Notebooks, Lawrence \& Wishart (1971): and F.Parkin, Class nequality \& Political Order, McGibbon \& Kee (1971)

21. Eco, "Does the Eublic harm television?", op.cit.

23. Cf: J,Habermas, "Systematically Listorted Communications"。 $\perp_{n}$ kecent Sociology 2, ed.P.Dretzel.Collier-Mamillan (1970)

24. Cf: S.HaIl, "External/Internal Dialectic 'n Broadcasting", in Hourth Nymposium Un Broadcasting, Dept。 of Extra-mural 'tudies, U. of Manchester (1972)

25. Cf: L.Althusser, "Ideological Nate Apparatuses", in Lenin\& Philo-sophy, And Uther Essays. New Lefi Books. (1971). 